into orbit. Andrzej Wajda's acclaimed film Katyń (2007), about the Soviet massacre of Polish troops in 1940, is informed by a forensic investigation of their mass grave. But not all is dark and Slavic. The French comedy La Très Très Grande Entreprise (directed by Pierre Jolivet, on general release next month), about workers who sue an agrochemical company for polluting their pond, is Erin Brockovich played for laughs. And Chilean Ricardo Larraín's Chile Puede (2008) tells the story of an unfortunate cosmonaut stranded in space by his own countrymen.

The festivals show that there are many ways to get research right at the movies. "When you make a film, you want the science to be wrapped around a story," said Gambis of the Imagine festival. "I don't think you have to distort science to make it exciting." Jascha Hoffman is a writer based in New York. e-mail: jascha@jaschahoffman.com

\title{
Neutrinos: wonderful or crass?
}

\section{John Updike's 1960 poem vents frustration at the detached and elusive quantum particles that have no consideration for our earthly perceptions, says Martin Kemp.}

The torrent of words and images triggered by the huge publicity campaign accompanying the launch of the Large Hadron Collider at CERN, the particle-physics laboratory near Geneva, Switzerland, has served to stress the gulf between cutting-edge physics and public understanding. Terms such as 'quantum leap' and 'Big Bang' have entered our popular vocabulary. Many people are able to recognize the appearance of particle collisions from the familiar etched repertoire of lines, arcs, spirals and fusillades of points. But whether most of us can really visualize these phenomena in terms that relate to our experience is another matter.

We are evolutionarily equipped to master visible and touchable space to an extraordinary degree. But we have always experienced difficulty with the immensely big and minutely small, and the infinite lies definitively beyond the reach of our standard perceptions. In the Middle Ages, this dilemma was resolved by distinguishing between the indefinitely large and unknowable infinity, which was identified with God. The mathematician Georg Cantor still used this basic distinction in the late $1880 \mathrm{~s}$ when he protested that his set theory was not in conflict with theology.

Finite reason and infinite revelation could each occupy their own territories in the traditional Christian solution. Something of this separation is signalled in John Updike's neat aphorism "Gods do not answer letters" in a 1960 article in The New Yorker - the god in this case was the baseball star Ted Williams.

The worlds disclosed by physics and astronomy have progressively taken us into realms where the separation of indefiniteness and infinity is no longer sustainable. They have also taken us into intellectual oceans where non-specialists swim in a sea of cosmic bewilderment. This sense is perfectly captured in Updike's poem Cosmic Gall, published in The New Yorker on 17 December 1960, and now often billed as the physicist's favourite poem.

Updike, so prolific and varied as to resist ready encapsulation, is famed for his refined, lyrical and forensic treatment of small communities, centred on the fictional town of Alton, Pennsylvania. His 'Rabbit' series of novels and his 1984 book The Witches of Eastwick, later made into a film, have reached a public beyond the specialist world of high literature.

Cosmic Gall is both well informed and infused by an underlying irritation about the
Cosmic Gall
by John Updike
Neutrinos they are very small.
They have no charge and have no mass
And do not interact at all.
The earth is just a silly ball
To them, through which they simply pass,
Like dustmaids down a drafty hall
Or photons through a sheet of glass.
They snub the most exquisite gas,
Ignore the most substantial wall,
Cold-shoulder steel and sounding brass,
Insult the stallion in his stall,
And, scorning barriers of class,
Infiltrate you and me! Like tall
And painless guillotines, they fall
Down through our heads into the grass.
At night, they enter at Nepal
And pierce the lover and his lass
From underneath the bed - you call
It wonderful; I call it crass.

counter-experiential nature of modern physics. It concerns the neutrino, the particle proposed by Wolfgang Pauli in 1930 and subsequently named by Enrico Fermi. Its existence was ingeniously adduced by Pauli to save the laws of conservation of energy and momentum in the face of energy loss in the products of radioactive $\beta$-decay. The particle's presence had not been observed, but Pauli speculated that its lack of mass and disinclination to interact would result in its undetectability.

We now know a good deal more about the ubiquitous but furtive neutrino particles, not least courtesy of three sets of Nobel prize winners: Leon Lederman, Melvin Schwartz and Jack Steinberger in 1988; Martin Perl and Frederick Reines in 1995; and Raymond Davies and Masatoshi Koshiba in 2002. We know that neutrinos have a very small amount of mass, that they acquire three 'flavours' that are interchangeable through oscillations, and that about $10^{14}$ neutrinos from the Sun and $10^{3}$ neutrinos in cosmic rays pass through our bodies each second.

Their elusiveness is part of their fascination. In the anthropometric vocabulary that lurks in the literature of nuclear physics, neutrinos feature as 'ghosts', 'poltergeists' and 'phantoms' — to say nothing of the 'personalities' they are accorded in physicists' conversations.

Updike opens with a nursery rhyme or limerick sentence, and then bounces through the poem with a series of rapid repetitions - mass, pass, glass, gas, class, lass, crass, all, ball, hall, wall, stall, tall, fall, call and even Nepal. The apparent randomness of his examples highlights the lack of discrimination and extreme disinterestedness of the wandering neutrinos.

We sense a perverse degree of relish for the neutrinos' detachment from our daily realities, our Earth-bound perceptions and engrossing passions - and those of the stallions in their stalls. "Dustmaids down a drafty hall" is a suggestively rich image, relating to no known job description but clear in meaning by analogy to dustmen.

But should physicists really like the poem? It seems to reverse their enchanted perspective. Its 19 lines are suffused by Updike's frustration at the impersonal way that neutrinos take no notice of us, living their own non-interactive lives, if such a life is a life at all. At the end, he contrasts the scientists' wonder with his own sense that such neutrality is crass.

Perhaps a physicist who has pinned the poem on the laboratory wall can take comfort from the potential ambiguity of the "It" in the last line. Maybe the "lover and his lass" are crass. But given Updike's human values, I think not.

Martin Kemp is research professor in the history of art at the University of Oxford, Oxford OX11PT, UK. 